\section{British Cardiac Society}

The Annual General Meeting will take place in Torquay on 22 to 25 May 1990.

\section{Cardiac ultrasound}

The 4th Bristol Cardiac Ultrasound Course will be held at Bristol General Hospital. There are two modules which can be attended individually if desired: on 12 and 13 July 1989 on Cardiac imaging ( $M$ mode and cross sectional) and on 14 and 15 July 1989 on Doppler echocardiography (including colour flow). Further details from Dr Peter Wilde, Consultant Radiologist, Department of Radiodiagnosis, Bristol Royal Infirmary, Bristol BS2 8HW. Telephone (0272) 230000 Ext 2130.

\section{Pakistan Cardiac Society}

The 9th biennial International Congress of Cardiology organised by the Pakistan Cardiac Society will take place in Lahore on 7 to 10 December 1989. For information write to the organising secretary of the Congress at the Department of Cardiology, Mayo Hospital, Lahore, Pakistan.

\section{Correction}

Cardiac surgery for patients aged 65 years and older: a long term survival analysis $S$ Livesey, $N$ Caine, $D J$ Spiegelhalter, $T A H$ English, $J$ Wallwork-The authors apologise for omitting in their paper published in the December 1988 issue (volume 60: pages $480-4)$ thanks to Mr B B Milstein for his help and acknowledgement to the cardiologists at Papworth Hospital who selected and referred the patients for operation. 